\title{
Antibiotic Prophylaxis for Leptospirosis
}

David Brett-Major

University of Nebraska Medical Center, david.brettmajor@unmc.edu

Robert J. Lipnick

Armed Forces Health Surveillance Center

Tell us how you used this information in this short survey.

Follow this and additional works at: https://digitalcommons.unmc.edu/coph_epidem_articles

Part of the Epidemiology Commons

\section{Recommended Citation}

Brett-Major, David and Lipnick, Robert J., "Antibiotic Prophylaxis for Leptospirosis" (2009). Journal Articles: Epidemiology. 21.

https://digitalcommons.unmc.edu/coph_epidem_articles/21

This Article is brought to you for free and open access by the Epidemiology at DigitalCommons@UNMC. It has been accepted for inclusion in Journal Articles: Epidemiology by an authorized administrator of DigitalCommons@UNMC.For more information, please contact digitalcommons@unmc.edu. 


\section{(E) Cochrane Library}

Cochrane Database of Systematic Reviews

\section{Antibiotic prophylaxis for leptospirosis (Review)}

Brett-Major DM, Lipnick RJ

Brett-Major DM, Lipnick RJ.

Antibiotic prophylaxis for leptospirosis.

Cochrane Database of Systematic Reviews 2009, Issue 3. Art. No.: CD007342.

DOI: 10.1002/14651858.CD007342.pub2.

www.cochranelibrary.com 


\section{TABLE OF CONTENTS}

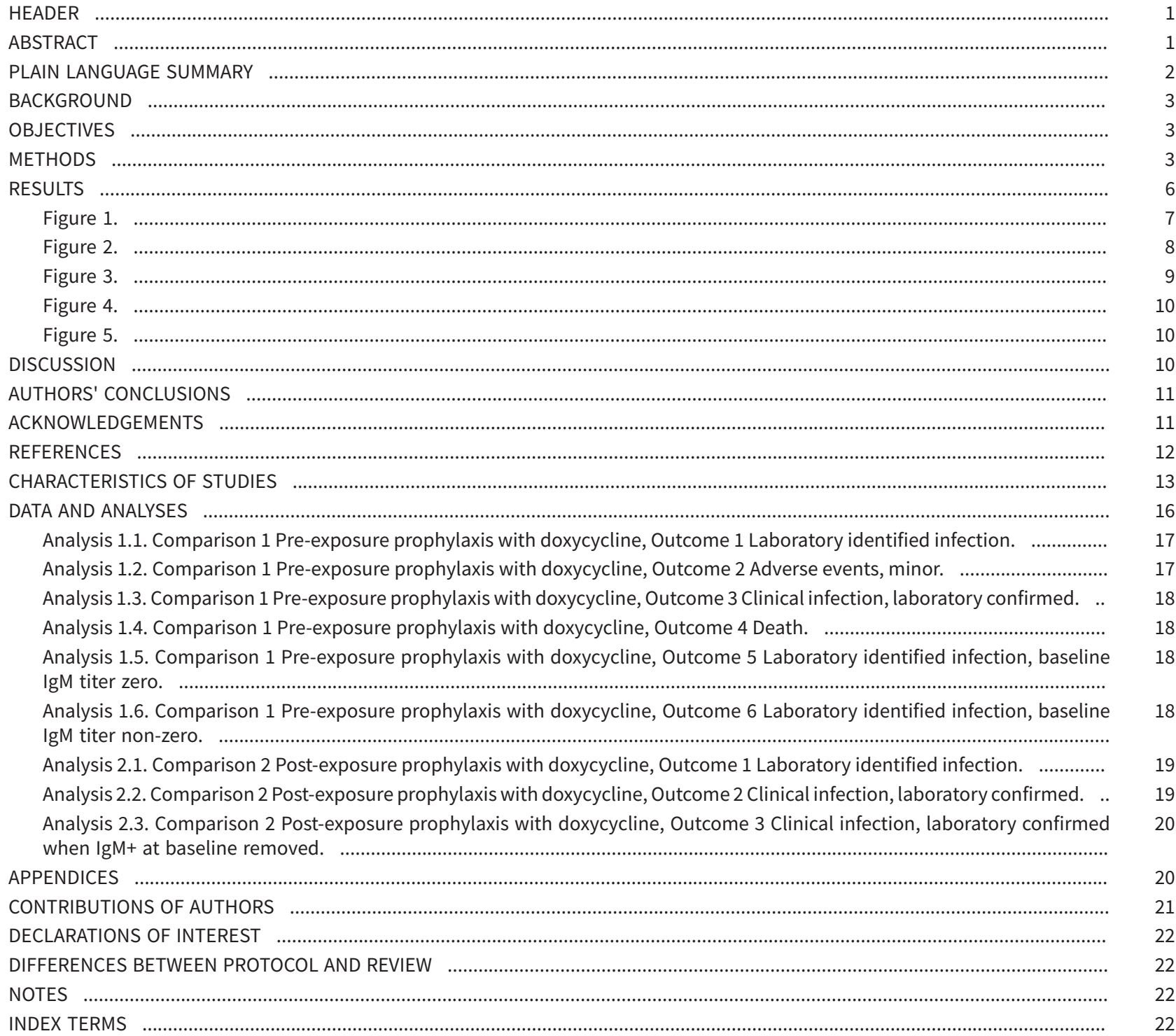


[Intervention Review]

\title{
Antibiotic prophylaxis for leptospirosis
}

David M Brett-Major ${ }^{1}$, Robert J Lipnick²

1Military Tropical Medicine Course, NAVMED MPT\&E, Bethesda, MD, USA. ${ }^{2}$ Communications, Standards, \& Training Division, Armed Forces Health Surveillance Center, Silver Spring, MD, USA

Contact address: David M Brett-Major, Military Tropical Medicine Course, NAVMED MPT\&E, 8901 Wisconsin Avenue, Bethesda, MD, 20889-5611, USA.dmbrettmajor@gmail.com, David.Brett-Major@med.navy.mil.

Editorial group: Cochrane Hepato-Biliary Group.

Publication status and date: New, published in Issue 1, 2010.

Citation: Brett-Major DM, Lipnick RJ. Antibiotic prophylaxis for leptospirosis. Cochrane Database of Systematic Reviews 2009, Issue 3. Art. No.: CD007342. DOI: 10.1002/14651858.CD007342.pub2.

Copyright (c) 2010 The Cochrane Collaboration. Published by John Wiley \& Sons, Ltd.

\begin{abstract}
A B S T R A C T

\section{Background}

Leptospira infection is a global zoonosis with significant health impact for agricultural workers and those persons whose work or recreation takes them into endemic areas.
\end{abstract}

\section{Objectives}

This systematic review assessed the current literature for evidence for or against use of antibiotic prophylaxis against Leptospira infection (leptospirosis).

\section{Search methods}

The authors searched The Cochrane Hepato-Biliary Group Controlled Trials Register, the Cochrane Central Register of Controlled Trials (CENTRAL) in The Cochrane Library, MEDLINE, EMBASE, and SCI-Expanded as well as relevant professional society meeting abstracts until January 2009.

\section{Selection criteria}

Prospective, randomised clinical trials studying antibiotic prophylaxis against leptospirosis were selected.

\section{Data collection and analysis}

Data collection abstracted participant demographics and outcomes as well as features of trial design and quality. Trial results were analysed to independently determine outcomes, while multiple trial data was pooled when relevant.

\section{Main results}

Three trials were included, all of which evaluated doxycyline use. Trial quality suffered from a lack of intention-to-treat analysis and variability across trials in methodology and targeted outcomes. One trial assessed post-exposure prophylaxis in an indigenous population after a flood without apparent efficacy in reduction of clinical or laboratory identified Leptospira infection. Two trials assessed pre-exposure prophylaxis, one among deployed soldiers and another in an indigenous population. Despite an odds ratio of 0.05 ( $95 \% \mathrm{Cl} 0.01$ to 0.36 ) for laboratory-identified infection among deployed soldiers on doxycyline in one of these two trials, pooled data showed no statistically significant reduction in Leptospira infection among participants (Odds ratio 0.28 (95\% $\mathrm{Cl} 0.01$ to 7.48 ). Minor adverse events (predominantly nausea and vomiting) were more common among those on doxycycline with an odds ratio of $11(95 \% \mathrm{Cl} 2.1$ to 60$)$. 


\section{Authors' conclusions}

Regular use of weekly oral doxycycline $200 \mathrm{mg}$ increases the odds for nausea and vomiting with unclear benefit in reducing Leptospira seroconversion or clinical consequences of infection.

\section{PLAIN LANGUAGE SUMMARY}

\section{Use of antibiotics may or may not prevent leptospirosis}

This is a systematic review of clinical research testing whether taking the antibiotic can prevent infection from a water-borne bacteria called Leptospira. Data from different trials had conflicting results, and these trials targeted different kinds of people - travellers and people who live in at risk areas, encompassing soldiers, farmers, and students. Taken together, the data does not support the practice in all cases, though short term travellers with a potential for high risk exposure may be helped. People who took doxycycline were more likely to have stomach pain, nausea, and vomiting but the medication had to be stopped in only a few participants. 


\section{B A C K G R O U N D}

Leptospirosis is a global zoonosis caused by spirochetes of the genus Leptospira. The organism most commonly infects via entry through skin abrasion or oral intake (Bharti 2003; Pappas 2007). Those infected may exhibit a mild or sub-clinical illness, or manifest fulminant disease. It causes endemic disease among agricultural workers and others regularly exposed to flooded fields and livestock, or other sources of animal urine. Outbreaks occur among immune-naive individuals exposed because of changing environmental conditions, introduction of a new Leptospira species, travel, or occupational or recreational activities. Host immunity generally is species specific which has complicated development of effective vaccines (Bharti 2003).

In rural endemic areas exposure often begins in childhood with a significant asymptomatic seroconversion rate, as shown by a sera study in Viet Nam (Thai 2008). The disease rate often rises predictably in these settings following increased rainfall and sometimes in a single setting pathogens from multiple serotypes are represented (Pappachan 2004; Niwetpathomwat 2005). In the United States leptospirosis contributes only a small share of the water-borne outbreaks, though a recent outbreak happened on a Hawaiian college campus following flooding of a stream (Dziuban 2006; Gaynor 2007). Outbreaks may occur as focally as a single building as an Indian nurse's hostel experienced following water bin contamination (Ramakrishnan 2003).

Attack rates and hospitalisation rates often are high when immunenaive groups enter endemic areas with or without an active outbreak. Recently, $26 \%$ of Israeli troops training near the Jordan River and $37 \%$ of Peruvian troops who swam in a pond while training in rural Peru suffered acute leptospirosis (Russell 2003; Hadad 2006). An international outbreak occurred in 2003 when over three hundred Eco-Challenge competitors convened in Borneo. An estimated $40 \%$ of the 189 participants interviewed had fallen ill (Sejvar 2003). Fourteen recreational travellers in the Yaeyama Islands of Japan were hospitalised in another outbreak (Narita 2005).

Many of these settings - active outbreaks, high-risk travel, recent flooding in the setting of occupational exposure - represent predictable periods of increased disease risk. Personal protective measures such as antibiotic prophylaxis may have important roles in decreasing the incidence of leptospirosis. We could find no meta-analyses or non-Cochrane systematic review on antibiotic prophylaxis for leptospirosis. With this review we seek to define the role of prophylactic antibiotic use and update a previously published Cochrane systematic review by Guidugli et al (Guidugli 2000).

\section{O B JE C T IVES}

To assess the beneficial and harmful effects of antibiotics for prevention of leptospirosis.

\section{METHODS}

\section{Criteria for considering studies for this review \\ Types of studies}

We considered for inclusion all prospective, randomised clinical trials studying antibiotic prophylaxis against leptospirosis regardless of year, language, form of publication, or blinding (Higgins 2008).

We excluded cohort studies, case-control studies, and quasirandomised trials in analysis of benefit outcomes. We sought detection of harms in all study types, but only the identified trials had relevant data.

\section{Types of participants}

Agricultural workers in endemic regions, veterinarians, and other high-risk occupations as well as high-risk activity travellers, such as troops and eco-tourists, potentially exposed to Leptospira infection.

\section{Types of interventions}

Administration of antibiotic expressly given for the purpose of prophylaxis against leptospirosis versus placebo, no intervention, or another antibiotic.

We did not exclude studies based upon type of antibiotic, dose, dose interval, route of administration, or timing of dose, though these factors may impact pooling. We would have allowed cointerventions if they had been equally administered to all trial groups, but this did not arise.

\section{Types of outcome measures}

We studied the following outcome measures:

\section{Primary outcomes}

- Overall mortality.

- Leptospirosis mortality (confirmed by laboratory diagnosis).

- Hospitalisation (regardless of cause).

- Leptospirosis hospitalisation (confirmed by laboratory diagnosis).

- Among those with hospitalisation for leptospirosis confirmed by laboratory diagnosis, ventilator requirement.

\section{Secondary outcomes}

- Days lost from work or travel.

- Laboratory-diagnosed leptospirosis regardless of the presence of an identified clinical syndrome.

- Clinical diagnosis of leptospirosis regardless of the presence of laboratory confirmation.

- Clinical diagnosis of leptospirosis confirmed by laboratory diagnosis.

- Adherence to assigned intervention.

- All adverse events. An adverse event defined as any untoward medical occurrence in a patient in any trial group, regardless of association with the intervention, but result in a dose reduction, discontinuation of treatment, or registration as an adverse event (ICH-GCP 1996). We also assessed events, which are characterized by the following strata.

- Minor not requiring intervention.

- Minor requiring intervention.

- Requiring hospitalisation or resulting in long-term disability.

- Death (ICH-E3 1995). 


\section{Search methods for identification of studies}

We performed electronic and manual searches.

\section{Electronic searches}

We searched the following databases until January 2009: The Cochrane Hepato-Biliary Group Controlled Trials Register ( Gluud 2008), the Cochrane Central Register of Controlled Trials (CENTRAL) in The Cochrane Library, MEDLINE, EMBASE, and SCI-Expanded (Royle 2003). The search strategies with the time span of the searches are given in Appendix 1. We searched abstracts of the Infectious Diseases Society of America, American Society of Tropical Medicine and Hygiene, and International Society of Travel Medicine also for potential studies. Once we selected a study for inclusion, we used its bibliography to search for candidate studies. In MEDLINE, we used the 'Related Links' feature to search the 25 most related publications to each selected study.

We contacted authors of selected publications in order to request additional study information as needed to inform review of prespecified outcomes of the review. Correspondence was sent to the principal and senior authors of each selected study on 25 September 2008 without reply.

\section{Data collection and analysis}

The authors followed the instructions in The Cochrane Handbook for Systematic Reviews of Interventions (Higgins 2008) and The Cochrane Hepato-Biliary Group Module (Gluud 2008) for data collection and analysis.

\section{Selection of studies}

The principal author reviewed the entire list of candidate studies obtained by databases search for compliance with the selection requirements. At least one other author independently reviewed search results similarly prior to inclusion. While completing the study abstraction of selected studies under the following section, authors screened study references for other potential studies for inclusion.

\section{Data extraction and management}

We abstracted each selected study with two independent abstractions.

We extracted the following information from each selected study:

- Study and publication identifiers

- Database index number, first author, journal, year of publication, and language.

- Location, period of intervention, duration participants were followed.

- Funding source.

- Study design

- Inclusion and exclusion criteria.

- Sample size (premise, calculation).

- Outcome measures.

- Randomisation and how randomised participants were allocated across groups.

- Definitions of outcomes, in particular clinical and laboratory diagnosis.
- Assigned interventions and control.

- Who was blinded and how concealment was accomplished.

- Dichotomous: If not selected for inclusion for analysis of benefit, should it be abstracted to inform analysis of harms? (if yes, abstract).

- Dichotomous: If not selected for inclusion for analysis of benefit, should it be abstracted to inform the discussion? (if yes, abstract).

- Participant demographics

- Age.

- Sex.

- Nature of exposure (agricultural worker, eco-tourist, etc).

- Results

- Observed outcomes as published and augmented by author query.

- Follow-up.

- Completion rates by trial arms.

- Type of analysis (intention-to-treat sought).

\section{Assessment of risk of bias in included studies}

We abstracted selected studies without masking of the trial names. Two authors independently abstracted the data and discrepancies were mediated among the review group authors. The authors followed the instructions given in the Cochrane Handbook for Systematic Reviews of Interventions (Higgins 2008) and the Cochrane Hepato-Biliary Group Module (Gluud 2008). Due to the risk of biased overestimation of intervention effects in randomised trials with inadequate methodological quality (Schulz 1995; Moher 1998; Kjaergard 2001; Wood 2008), we looked at the influence of methodological quality of the trials on the results by evaluating the methodological components described below. If information was not available in the published trial, we contacted the authors in order to assess the trials correctly though without reply. Explicit methodologic grading criteria are recommended standard in the Cochrane Hepato-Biliary Group Module (Gluud 2008).

\section{Generation of the allocation sequence}

- Yes, adequate, sequence generation was achieved using computer random number generation or a random number table. Drawing lots, tossing a coin, shuffling cards and throwing dice are adequate if performed by an independent adjudicator.

- Unclear, the trial is described as randomised but the method of sequence generation was not specified.

- No, inadequate, the sequence generation method is not, or may not be, random. Quasi-randomised studies, those using dates, names, or admittance numbers in order to allocate patients are inadequate and will be excluded for the assessment of benefits but not for harms.

\section{Allocation concealment}

- Yes, adequate, allocation was controlled by a central and independent randomisation unit, opaque and sealed envelopes or similar, so that intervention allocations could not have been foreseen in advance of, or during, enrolment.

- Unclear, the trial was described as randomised but the method used to conceal the allocation was not described, so that intervention allocations may have been foreseen in advance of, or during, enrolment. 
- No, inadequate, if the allocation sequence was known to the investigators who assigned participants or if the study was quasi-randomised. Quasi-randomised studies will be excluded for the assessment of benefits but not for harms.

\section{Blinding}

- Yes, adequate, the trial was described as double blind and the method of blinding was described, so that knowledge of allocation was adequately prevented during the trial.

- Unclear, the trial was described as double blind, but the method of blinding was not described, so that knowledge of allocation was possible during the trail.

- No, not performed, the trial was not double blind, so that the allocation was known during the trail.

\section{Incomplete outcome data}

- Yes, adequate, the numbers and reasons for dropouts and withdrawals in all intervention groups were described or it was specified that there were no dropouts or withdrawals.

- Unclear, the report gave the impression that there had been no dropouts or withdrawals, but this was not specifically stated.

- No, inadequate, the number or reasons for dropouts and withdrawals were not described.

\section{Selective outcome reporting}

- Yes, adequate, pre-defined, or clinically relevant and reasonably expected outcomes are reported.

- Unclear, not all pre-defined, or clinically relevant and reasonably expected outcomes are reported or are not reported fully, or it is unclear whether data on these outcomes were recorded or not.

- No, inadequate, one or more clinically relevant and reasonably expected outcomes were not reported; data on these outcomes were likely to have been recorded.

\section{Any other bias}

- Yes, adequate, the trial appears to be free of other components that could put it at risk of bias.

- Unclear, the trial may or may not be free of other components that could put it at risk of bias.

- No, inadequate, there are other factors in the trial that could put it at risk of bias, e.g., no sample size calculation made, early stopping, industry involvement, or an extreme baseline imbalance.

We abstracted selected studies independently of each other and without masking of the trial names. We mediated discrepancies between each other. We used an abstraction form detailing information for global bias risk assessment and potential subgroup analyses.

We assessed selection and observation biases by abstracting core study methodologies to include inclusion and exclusion criteria, randomisation, blinding, outcome definitions, and follow-up. We used each study's enrolling definitions, duration of participant following, and surveillance methods in order to assess lead and lagtime biases.

\section{Dealing with missing data}

We planned to assess the effect of missing data on the primary outcome measures by applying a number of different scenarios to the intention-to-treat analyses as able from the available published and author supplemented data (Hollis 1999). These scenarios are described in The Cochrane Hepato-Biliary Group Module (Gluud 2008) and are defined as the following:

- Carry-forward analysis: for all participants with missing data, regardless of group, the last reported observed response will be used.

- Poor outcome analysis: assumes that all of the participants with missing data (from either group) had the outcome of interest.

- Good outcome analysis: assumes that none of the participants with missing data (from either group) had the outcome of interest.

- Extreme-case favouring antibiotic prophylaxis: assumes that none of the participants with missing data from the antibiotic group had the outcome of interest, whereas all of those from the control group had the outcome of interest.

- Extreme-case favouring control: assumes that all of the participants with missing data from the antibiotic group had the outcome of interest, whereas none from the control group had the outcome of interest.

\section{Assessment of heterogeneity}

We applied qualitative assessments for sources of heterogeneity, in particular $1^{2}$ of 75 per cent or greater was an indicator of considerable heterogeneity (Higgins 2008).

\section{Assessment of reporting biases}

Trials with adequate generation of allocation sequence, adequate allocation concealment, adequate blinding, adequate handling of incomplete outcome data, no selective outcome reporting, and without other bias risks were considered low-bias risk trials. Trials with one or more unclear or inadequate quality components were considered high-bias risk trials. However, we are aware that in a large number of reviews subsequent analysis separating low-bias and high-bias risk trial data may not be possible (Gluud 2008).

\section{Data synthesis}

We attempted to assess each outcome on an intention-to-treat basis, though the selected trials did not report the necessary data for this. Consequently, all analyses were on the sub-group for which outcomes were reported. Study context and methods were assessed to determine if pooling of their data was appropriate.

We used Cochrane's RevMan5 software to calculate individual and pooled studies' estimates of effect and included stability analysis for each outcome evaluated (RevMan 2008). We performed both fixed-effect and random-effects modelling. We reported the fixedeffect result if there was no difference between them. Otherwise, we reported both results.

\section{Subgroup analysis and investigation of heterogeneity}

We performed sub-group analyses when relevant, though it was not possible for most pre-defined sub-groups. We had planned subgroup analysis based upon patient demographics and assigned interventions. For instance, we lacked sufficient individual trial 
detail to determine the pooled effect for troops and rice farmers, respectively. Nor were several antibiotics employed.

Where considerable heterogeneity was present, we evaluated study differences such as patient population and study definitions.

\section{Sensitivity analysis}

Given the low number of selected studies, sensitivity analyses were not relevant. Had they been, we would have performed sensitivity analyses for pre-defined outcomes.

Potential analyses would have included:

- Trials with low risk of bias compared with trials with high risk of bias:

- By presence of adequate methodological components compared with unclear or inadequate components.

- By presence or absence of blinding.

- By presentation forum (abstracts versus peer-reviewed journal).

- By specificity of inclusion criteria.
- Iterative removal of trials from pooling to isolate sources of heterogeneity.

- Given sufficient number of selected trials (more than 10), we planned to perform funnel plot asymmetry analysis of trial size against antibiotic treatment in order to assess small-trial effects suggesting bias (Egger 1997).

\section{RES U L T S}

\section{Description of studies}

\section{Results of the search}

Execution of the search strategies delineated in Appendix 1 yielded 921 citations for title-abstract review with overlap across the databases. Excluded citations at this phase consisted predominantly of case reports, Leptospira therapy and vaccine studies including veterinary research, narrative reviews, and unrelated literature. Forty-one citations remained representing 24 unique published reports for full text evaluation. Three trials were included, while 21 studies were excluded as narrative reviews of the literature or of local experience assessing Leptospira outbreaks. The initial search query from June 2008 yield is represented in Figure 1. 
Figure 1. Search results by database. CHBG- Cochrane Hepato-Biliary Group.

\section{Antibiotic Prophylaxis Against Leptospirosis: Literature Search}

\begin{tabular}{lll} 
Review: Tite-Abstract $\quad$ Full Text Selected \\
\hline
\end{tabular}

Controlled Trials Registers

CHBB

Central

PubMed

Ovid

EMBASE

Sci-Expanded

IDSA On-Line Abstracts

ASTMH On-Line Abstracts

ISTM On-Line Abstracts
14

30

201

504

121

3

4

38

7
2

3

2

3

3

$15 \quad 3$

42

10

0

0

$7 \quad 0$

Unique Studies: 24
The published literature search was updated in January 2009 using a MEsH strategy on the same search engines without a change in study selection. This repeat search yielded 73 articles: 2 selected studies (the third by bibliographic review), 4 of topics other than leptospirosis, 50 case reports, reviews, and commentaries, 11 trials of non-human research, 5 general epidemiologic studies, and 1 human trial not addressing antibiotic prophylaxis.

\section{Included studies}

Details of included trials are consolidated in the 'Characteristics of Studies' tables. All three trials used doxycycline as experimental prophylaxis. Two of the trials represented assessment of preexposure prophylaxis (Takafuji 1984; Sehgal 2000), while a third assessed post-exposure prophylaxis (Gonsalez 1998). One trial utilised antibiotic prophylaxis in the setting of time-limited exposure among troops (Takafuji 1984), while the remaining two trials enrolled participants from among an endemic population (Gonsalez 1998; Sehgal 2000). While all three of the included trials included mechanisms to assess clinical disease, their study design focused on laboratory identified infection and clinical outcome data were underreported.

\section{Excluded studies}

There were no other studies of antibiotic prophylaxis for leptospirosis identified, and the remaining literature did not provide additional data on adverse events.

\section{Risk of bias in included studies}

Assessment of risk of bias is delineated for each included study in the 'Characteristics of Studies' tables as well as presented graphically on Figure 2 and Figure 3 . All three included trials utilized Pfizer provided medications; however, the degree of funding 
support beyond this was unclear. In addition to the information provided in the tables, the study performed by Takafuji 1984 et al risked significant lag-time bias for clinical outcomes in the dispersion of troops from the endemic training area (Takafuji
1984). The investigators attempted to minimise this by detailing clear instructions to participants for presenting for care if they experienced symptoms (Takafuji 1984).

\section{Figure 2. Methodological quality graph: review authors' judgements about each methodological quality item} presented as percentages across all included studies.

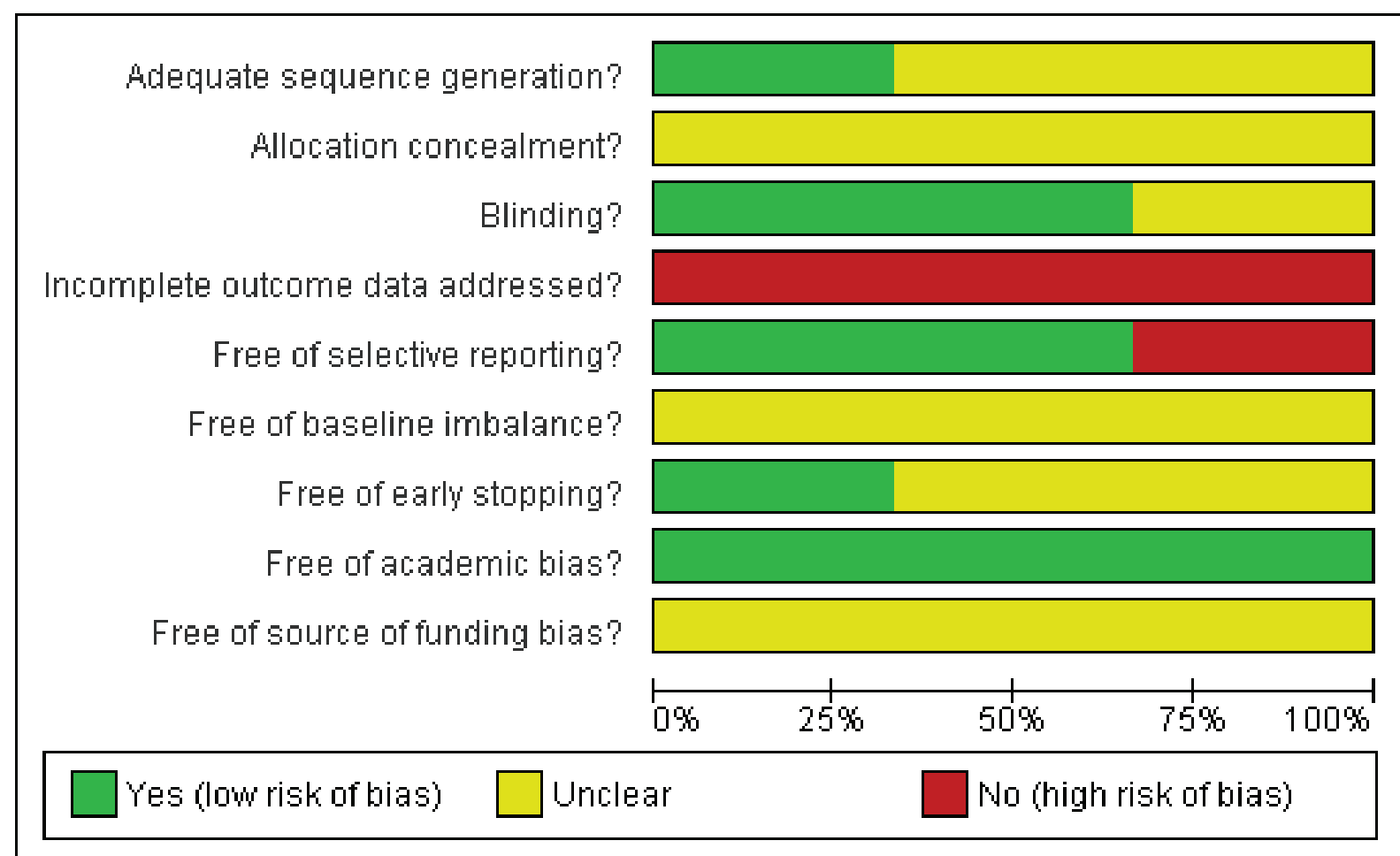


Figure 3. Methodological quality summary: review authors' judgements about each methodological quality item for each included study.

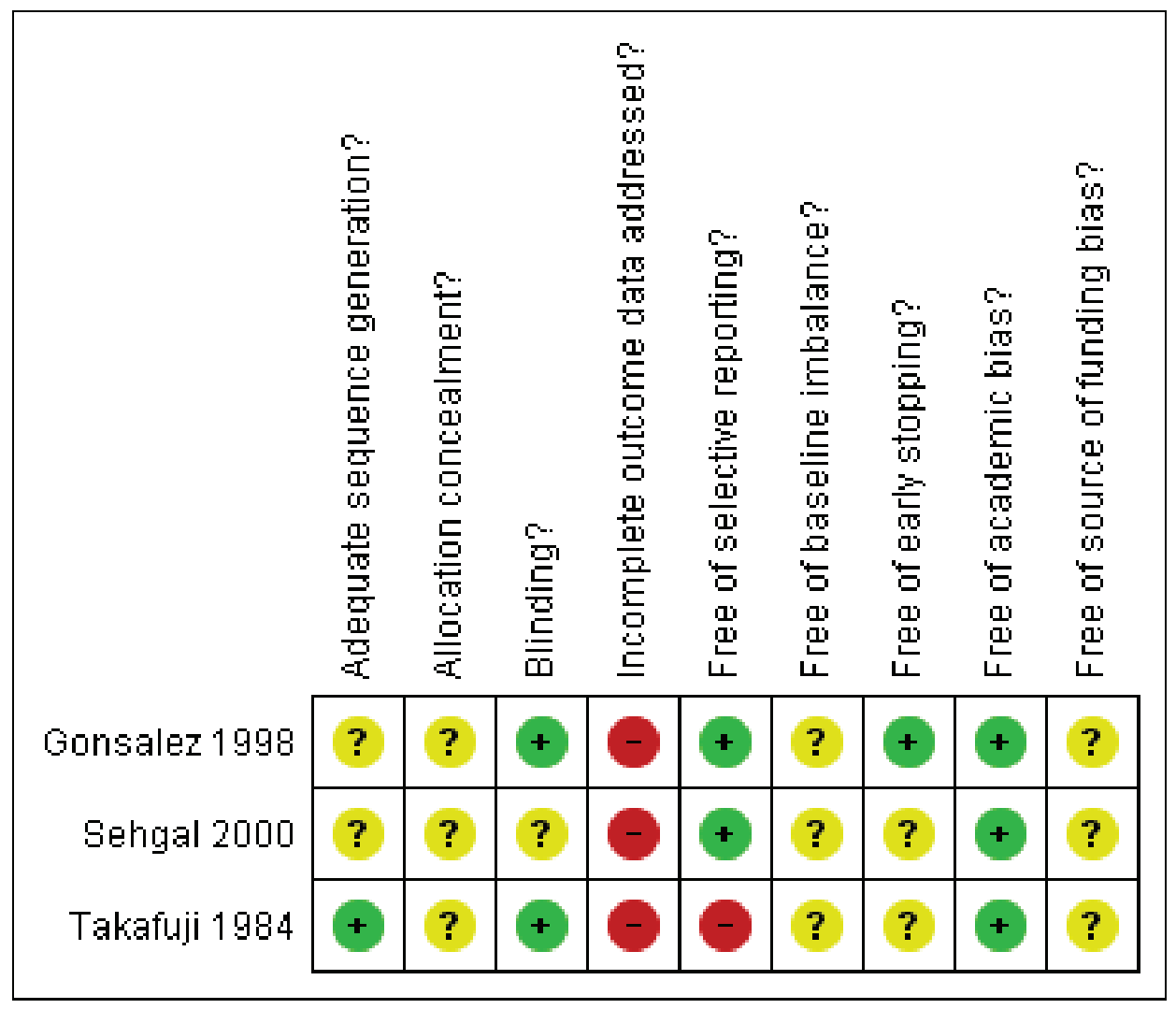

\section{Allocation}

The method of allocation concealment was unclear in all the three trials (Takafuji 1984; Gonsalez 1998; Sehgal 2000). Only one trial disclosed its method for sequence generation and it was appropriate (Takafuji 1984).

\section{Blinding}

Takafuji 1984 et al reported use of a double-blind trial design. Gonsalez 1998 et al used blinding of its laboratory personnel, but whether clinical evaluators were blinded was not disclosed. Sehgal 2000 et al reported use of blinding but it was not further described.

\section{Incomplete outcome data}

Only one trial identified its primary outcome and reported a power analysis (Sehgal 2000). None of the trials provided complete data on clinical and laboratory outcomes, and intention-to-treat data in particular was lacking

\section{Selective reporting}

Two of the three studies were free of selective reporting (Gonsalez 1998; Sehgal 2000). One of the trials reported on clinical events but mixed events from enrolled and not-enrolled patients (Takafuji 1984).

\section{Other potential sources of bias}

None of the three included trials provided sufficient data to complete intention-to-treat analyses. All three of the trials may have yielded non-differential misclassification in their broad withdrawal criteria, which excluded from analysis participants with an intervening illness or antibiotic prescription. The method by which they excluded leptospirosis in these withdrawn participants was not reported.

\section{Effects of interventions}

With the exception of death (Sehgal 2000), the planned primary outcome measure analyses for this review could not be assessed. Results of analysis of the extractable secondary outcomes are described in the 'Data and analyses' tables, and pooled results in Figure 4 and Figure 5. Only data for two outcomes were amenable to pooling: laboratory identified infection and adverse events, minor (Takafuji 1984; Sehgal 2000). RevMan 5 software yielded MantelHaentzel odds ratios as shown in Data and analyses and further described here. 
Figure 4. Forest plot of comparison: 1 Pre-Exposure Prophylaxis with Doxycycline, outcome: 1.1 Laboratory Identified Infection.

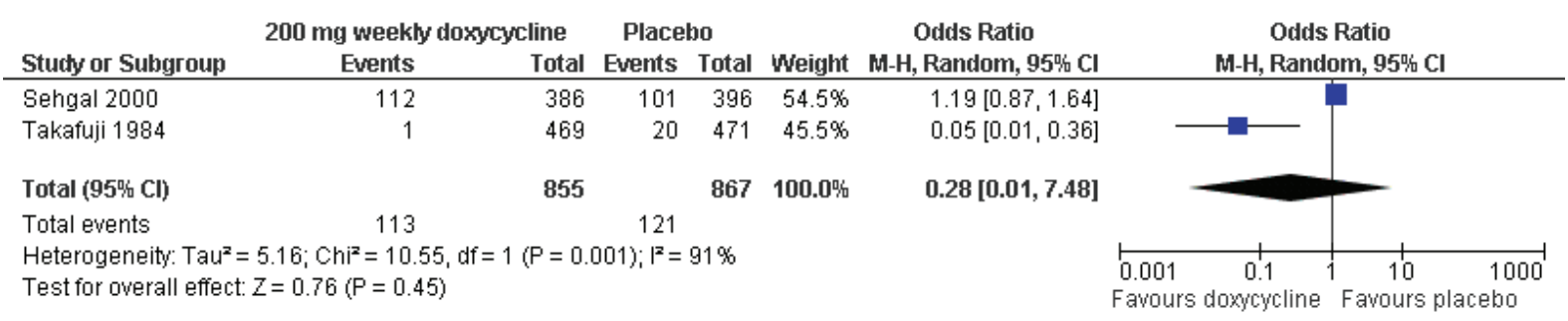

Figure 5. Forest plot of comparison: 1 Pre-Exposure Prophylaxis with Doxycycline, outcome: 1.2 Adverse Events, Minor.

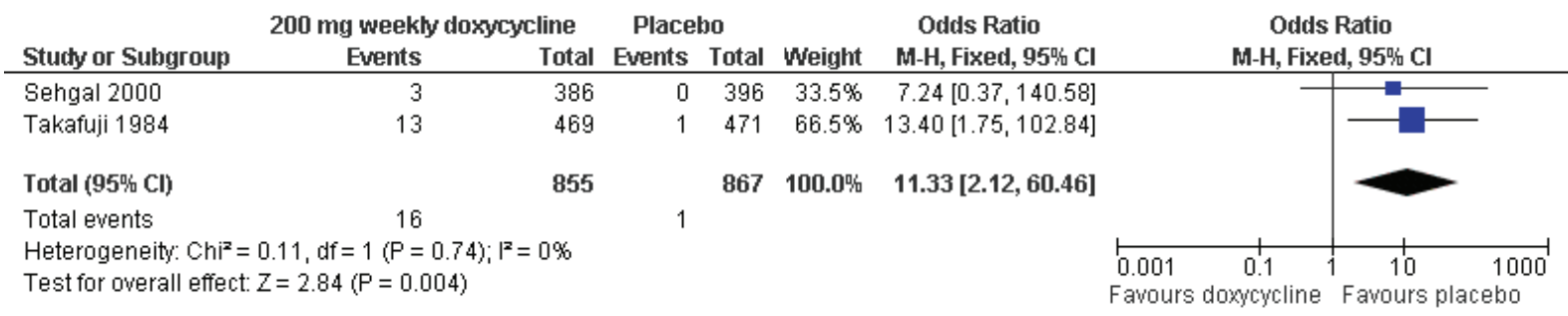

In a single trial of pre-exposure prophylaxis, the odds of death were decreased among those on doxycycline therapy though the result did not achieve statistical significance, OR 0.15 (95\% Cl 0.01 to 2.83) - death was a rare event with three deaths occuring among 396 controls, and no deaths among the 386 persons in the intervention group (Sehgal 2000).

In the case of laboratory identified infection, heterogeneity was high. Random-effects modelling, which is demonstrated in Analysis 1.1 and Figure 4, yielded OR $0.28(95 \% \mathrm{Cl} 0.01$ to 7.48$)$. Fixedeffects modelling for this outcome yielded OR $0.94(95 \% \mathrm{Cl} 0.70$ to 1.27$)$. Laboratory identified infection carried a point estimate odds which favoured pre-exposure prophylaxis though this did not reach statistical significance. Pre-exposure and post-exposure prophylaxis study data were not pooled as their roles in intervening in the pathologic pathway differ. Event rates are reported in the figure.

In one of the two trials of pre-exposure prophylaxis (Sehgal 2000) and the trial of post-exposure prophylaxis (Gonsalez 1998), baseline IgM serum positivity status did not statistically significantly impact doxycycline's effect on the odds of laboratory identified infection. The one trial that evaluated post-exposure prophylaxis achieved no statistically significant results (Gonsalez 1998).

Therapy increased the odds of minor adverse events with OR 11.33 (95\% Cl 2.12 to 60.46), in particular nausea and vomiting, which occasionally required the discontinuing of antibiotic prophylaxis (Takafuji 1984; Sehgal 2000).

\section{DISCUSSION}

\section{Summary of main results}

Pre-exposure antibiotic prophylaxis with doxycycline may decrease laboratory identified Leptospira infection.
Minor adverse events such as nausea and vomiting are more likely in the setting of doxycycline administration.

\section{Overall completeness and applicability of evidence}

The current evidence lacks sufficient data on clinical outcomes other than minor adverse events. The goal of a prophylaxis regimen in a patient is not to limit laboratory infection, but rather to allow accomplishment of mission, completion of enjoyable travel, or prevention of lost days at work or decreased productivity, not to mention severe outcomes of disease to include hospitalisation, intubation, and death. While at times elegant in design, the included trials are proof of concept trials and should encourage more robust evaluation. This is particularly true in areas where severe leptospirosis is common, but intensivist medical care services are limited.

While the pooled data here has use, the two populations were dramatically different. Takafuji et al evaluated highly trained, well nourished, fit adult men entering a hazard area for leptospirosis for a discrete period (Takafuji 1984). Sehgal et al assessed a more variable population including adolescents with long-term exposure risks and potentially other challenges (Sehgal 2000). The evidence for efficacy may not be applicable to both populations - note the high degree of heterogeneity in Analysis 1.1. And, the feasibility and risks of long-term therapy among an endemic population likely are different than that for short-term travellers.

\section{Quality of the evidence}

The current evidence is hampered by a lack of intention-to-treat data, and the possibility that they misclassified participants with leptospirosis as having non-related intervening illness or cause for antibiotic prescription. Only Sehgal et al clearly identified a primary outcome (seroconversion) and reported a power analysis (Sehgal 2000). The included trials also demonstrated inadequacies 
regarding randomisation and blinding, which may increase the risk of bias (Wood 2008).

\section{Potential biases in the review process}

This review was assisted by a broad search strategy and significant language translation support. However, the authors of the selected trials did not provide supplemental trial information for which we asked them by letter. The included trials may have had significant clarifying methods and results data that we could not obtain.

\section{Agreements and disagreements with other studies or reviews}

This review differs from its predecessor in two ways (Guidugli 2000). Firstly, data from use of doxycycline pre-exposure and post-exposure prophylaxis were not pooled. This was due to the destructive difference in the clinical situation. Secondly, one of the three included trials was not available for the previous review (Sehgal 2000).

\section{AUTHORS' CONCLUSIONS}

\section{Implications for practice}

Regular use of weekly doxycycline $200 \mathrm{mg}$ oral therapy has increased odds for nausea and vomiting with unclear benefit in reducing Leptospira seroconversion or clinical consequences of infection. If it is efficacious in reducing disease, it may be more so in travellers rather than in residents of an endemic area.

\section{Implications for research}

In addition to potentially evaluating other antibiotic therapies, larger trials should be designed to assess clinical outcomes in the setting of prophylactic therapy against Leptospirosis. These clinical outcomes should include health-care utilization (hospitalisation, ventilation, renal replacement therapy) and patient-centred outcomes (days lost from work and death). Preexposure rather than post-exposure prophylaxis research may be more likely to yield useful results. However, post-exposure prophylaxis has the potential to assist public health programs in population management during and after floods. Particularly in the testing of interventions among an endemic population, serovar specific baseline and infection testing should be performed. Future randomised trials need to be reported according to the CONSORT guidelines (http://www.consort-statement.org).

\section{ACKNOWLEDGEMENTS}

D Nikolova, Denmark for significant liaison and quality assurance efforts. Cochrane staff at three international offices provided translation support.

Peer Reviewers: Helena Maltezou, Greece; Georgios Pappas, Greece; Valentin Kolarski, Bulgaria; Bibiana Vanasco, Argentina. Contact Editor: Christian Gluud, Denmark. 


\section{R E F E R E N C E S}

\section{References to studies included in this review}

Gonsalez 1998 \{published data only (unpublished sought but not used)\}

Gonsalez CR, Casseb J, Monteiro FG, Paula-Neto JB, Fernandez RB, Silva MV, et al. Use of doxycycline for leptospirosis after high-risk exposure in São Paulo, Brazil. Revista do Instituto de Medicina Tropical de São Paulo 1988;40(1):59-61.

Sehgal 2000 \{published data only (unpublished sought but not used)\}

Sehgal SC, Sugunan AP, Murhekar MV, Sharma S, Vijayachari P. Randomized controlled trial of doxycycline prophylaxis against leptospirosis in an endemic area. International Journal of Antimicrobial Agents 2000;13(4):249-55.

Takafuji 1984 \{published data only (unpublished sought but not used)\}

Takafuji ET, Kirkpatrick JW, Miller RN, Karwacki JJ, Kelley PW, Gray MR, et al. An efficacy trial of doxycycline chemoprophylaxis against leptospirosis. New England Journal of Medicine 1984;310(8):497-500.

\section{Additional references}

\section{Bharti 2003}

Bharti AR, Nally JE, Ricaldi JN, Matthias MA, Diaz MM, Lovett MA, et al. Leptospirosis: a zoonotic disease of global importance. The Lancet Infectious Diseases 2003;3(12):757-71.

\section{Dziuban 2006}

Dziuban EJ, Liang JL, Craun GF, Hill V, Yu PA, Painter J, et al. Surveillance for waterborne disease and outbreaks associated with recreational water - United States, 2003-2004. Morbidity Mortality Weekly Report Surveillance Summaries 2006;55(12):1-30.

\section{Egger 1997}

Egger M, Davey Smith G, Schneider M, Minder C. Bias in metaanalysis detected by a simple, graphical test. British Medical Journal (Clinical Research Ed.) 1997;315:629-34.

\section{Gaynor 2007}

Gaynor K, Katz AR, Park SY, Nakata M, Clark TA, Effler PV. Leptospirosis on Oahu: an outbreak associated with flooding of a university campus. The American Journal of Tropical Medicine and Hygiene 2007;76(5):882-5.

\section{Gluud 2008}

Gluud C, Nikolova D, Klingenberg SL, Whitfield K, Alexakis N, Als-Nielsen B, et al. Cochrane Hepato-Biliary Group. About The Cochrane Collaboration (Cochrane Review Groups (CRGs)). 2008, Issue 4. Art. No.: LIVER.

\section{Guidugli 2000}

Guidugli DF, Castro AA, Atallah AN. Antibiotics for preventing leptospirosis. Cochrane Database of Systematic Reviews 2000, Issue 4. [DOI: 10.1002/14651858.CD001305]

\section{Hadad 2006}

Hadad E, Pirogovsky A, Bartal C, Gilad J, Barnea A, Yitzhaki S, et al. An outbreak of leptospirosis among Israeli troops near the Jordan River. The American Journal of Tropical Medicine and Hygiene 2006;74(1):127-31.

\section{Higgins 2008}

Higgins JPT, Green S (editors). Cochrane Handbook for Systematic Reviews of Interventions Version 5.0.0 [updated February 2008]. The Cochrane Colloboration, 2008. Available from www.cochrane-handbook.org.

\section{Hollis 1999}

Hollis S, Campbell F. What is meant by intention to treat analysis? Survey of published randomised controlled trials. BMJ (Clinical Research Ed.) 1999;319:670-4.

\section{ICH-E3 1995}

ICH harmonized tripartite guideline. Guideline on structure and content of clinical study reports (E3). Geneva: International Conference on Harmonization of Technical Requirements for Registration of Pharmaceuticals for Human Use. http:// www.ich.org/LOB/media/MEDIA479.pdf (accessed 19 May 2008) 1995.

\section{ICH-GCP 1996}

$\mathrm{ICH}$ harmonised tripartite guideline. Guideline for good clinical practice E6 (R1). Geneva: International Conference on Harmonisation of Technical Requirements for Registration of Pharmaceuticals for Human Use. www.ich.org/LOB/media/ MEDIA482.pdf (accessed 15 May 2008) 1996.

\section{Kjaergard 2001}

Kjaergard LL, Villumsen J, Gluud C. Reported methodologic quality and discrepancies between large and small randomized trials in meta-analyses. Annals of Internal Medicine 2001;135:982-9.

\section{Moher 1998}

Moher D, Pham B, Jones A, Cook DJ, Jadad AR, Moher M, et al. Does quality of reports of randomised trials affect estimates of intervention efficacy reported in meta-analyses?. Lancet 1998;352:609-13.

\section{Narita 2005}

Narita M, Fujitani S, Haake DA, Paterson DL. Leptospirosis after recreational exposure to water in the Yaeyama islands, Japan. The American Journal of Tropical Medicine and Hygiene 2005;73(4):652-6.

\section{Niwetpathomwat 2005}

Niwetpathomwat A, Niwatayakul K, Doungchawee G. Surveillance of leptospirosis after flooding at Loei Province, Thailand by year 2002. The Southeast Asian Journal of Tropical Medicine and Public Health 2005;36 (Suppl 4):202-5.

\section{Pappachan 2004}

Pappachan MJ, Sheela M, Aravindan KP. Relation of rainfall pattern and epidemic leptospirosis in the Indian state of

Antibiotic prophylaxis for leptospirosis (Review) 
Kerala. Journal of Epidemiology and Community Health 2004;58(12):1054.

\section{Pappas 2007}

Pappas G, Papadimitriou P, Siozopoulo V, Christou L, Akritidis N. The globalization of leptospirosis: worldwide incidence trends. International Journal of Infectious Diseases 2008;12(4):351-7. [MEDLINE: 18055245]

\section{Ramakrishnan 2003}

Ramakrishnan R, Patel MS, Gupte MD, Manickam P, Venkataraghavan S. An institutional outbreak of leptospirosis in Chennai, South India. The Journal of Communicable Diseases 2003;35(1):1-8

\section{RevMan 2008 [Computer program]}

The Nordic Cochrane Centre, The Cochrane Collaboration. Review Manager (RevMan). Version 5.0. Copenhagen: The Nordic Cochrane Centre, The Cochrane Collaboration, 2008.

\section{Royle 2003}

Royle P, Milne R. Literature searching for randomized controlled trials used in Cochrane reviews: rapid versus exhaustive searches. International Journal of Technology Assessment in Health Care 2003;19(4):591-603.

\section{Russell 2003}

Russell KL, Montiel Gonzalez MA, Watts DM, Lagos-Figueroa RC, Chauca G, Ore M, et al. An outbreak of leptospirosis among

\section{CHARACTERISTICS OF STUDIES}

Characteristics of included studies [ordered by study ID]
Peruvian military recruits. The American Journal of Tropical Medicine and Hygiene 2003;69(1):53-7.

\section{Schulz 1995}

Schulz KF, Chalmers I, Hayes RJ, Altman DG. Empirical evidence of bias. Dimensions of methodological quality associated with estimates of treatment effects in controlled trials. JAMA 1995;273:408-12.

\section{Sejvar 2003}

Sejvar J, Bancroft E, Winthrop K, Bettinger J, Bajani M, Bragg S, et al. Leptospirosis in "Eco-Challenge" athletes, Malaysian Borneo, 2000. Emerging Infectious Diseases 2003;9(6):702-7.

\section{Thai 2008}

Thai KT, Nga TT, Phuong HL, Giao PT, Hung le Q, Binh TQ, et al. Seroepidemiology and serological follow-up of antileptospiral IgG in children in Southern Vietnam. Acta Tropica 2008;106(2):128-31.

\section{Wood 2008}

Wood L, Egger M, Gluud LL, Schulz KF, Jüni P, Altman DG, et al. Empirical evidence of bias in treatment effect estimates in controlled trials with different interventions and outcomes: meta-epidemiological study. BMJ (Clinical Research Ed.) 2008;336(7644):601-5.

Gonsalez 1998

Methods Single site prospective, pilot, double-blinded randomised trial. Enrollees identified within 48 hours of a single flood.

Participants

Residents of rural Cabucu District, Sao Paolo Brazil. Ages ranged from 18 to 74 years. $41 \%$ of the participants were men. Exclusion criteria included suspected high risk exposure within the previous six months or allergy to tetracycline.

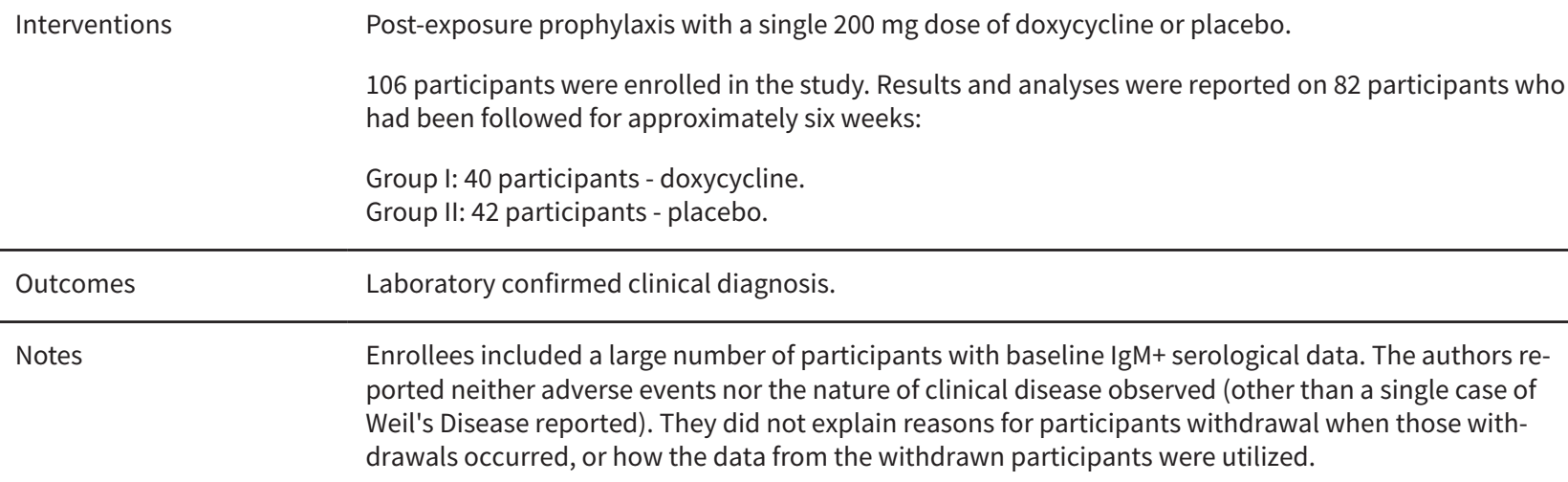

Risk of bias 
Gonsalez 1998 (Continued)

\begin{tabular}{lll} 
Bias & Authors' judgement & Support for judgement \\
\hline $\begin{array}{l}\text { Adequate sequence gener- } \\
\text { ation? }\end{array}$ & Unclear risk & Unclear. \\
\hline Allocation concealment? & Unclear risk & Unclear. \\
\hline $\begin{array}{l}\text { Blinding? } \\
\text { All outcomes }\end{array}$ & Low risk & Blinding asserted, though method not described. \\
\hline $\begin{array}{l}\text { Incomplete outcome data } \\
\text { addressed? }\end{array}$ & High risk & Twenty-four persons excluded from analysis. \\
\hline $\begin{array}{l}\text { All outcomes } \\
\text { Free of selective report- }\end{array}$ & Low risk & \\
\hline $\begin{array}{l}\text { Free of baseline imbal- } \\
\text { ance? }\end{array}$ & Unclear risk & $\begin{array}{l}\text { While primary and secondary outcomes were not clearly stated, they reported } \\
\text { on the outcomes most likely targeted by their study design. }\end{array}$ \\
\hline $\begin{array}{l}\text { Free of early stopping? } \\
\text { Free of academic bias? }\end{array}$ & Low risk & Relevant baseline demographics between groups not discussed. \\
\hline $\begin{array}{l}\text { Free of source of funding } \\
\text { bias? }\end{array}$ & Unclear risk & Yes. \\
\hline
\end{tabular}

\section{Sehgal 2000}

\begin{tabular}{ll}
\hline Methods & $\begin{array}{l}\text { Single site prospective, randomised trial. } \\
\text { The trial continued for } 12 \text { weeks, though the follow-up period for enrollees was unclear. }\end{array}$ \\
\hline Participants & $\begin{array}{l}\text { Area around Diglipur, Andaman Islands, India. Mix of residents including agricultural workers and ado- } \\
\text { lescent school children. Two out of three participants were between the ages of } 15 \text { and } 19 \text { years. Gen- } \\
\text { der distribution was not disclosed. Exclusion criteria included pregnancy, lactation, chronic disease, or } \\
\text { an ongoing medication regimen of any kind. }\end{array}$
\end{tabular}

\begin{tabular}{|c|c|}
\hline \multirow[t]{3}{*}{ Interventions } & $\begin{array}{l}\text { Pre-exposure prophylaxis with weekly administration of two doses of } 100 \mathrm{mg} \text { doxycycline spaced } \\
\text { twelve hours apart or vitamin B complex tablets (intended placebo). }\end{array}$ \\
\hline & 1025 participants were randomised into two groups, though analyses were reported on only 782 . \\
\hline & $\begin{array}{l}\text { Group I: } 386 \text { participants ( } 513 \text { enrolled) - doxycycline. } \\
\text { Group II: } 396 \text { participants ( } 512 \text { enrolled) - vitamin B complex tablets as placebo. }\end{array}$ \\
\hline
\end{tabular}

Outcomes The primary outcome was laboratory identified infection.

Notes Withdrawal criteria were broad and included any illness, a missed dose, or the prescription of additional antibiotics. Manner of exclusion of leptospirosis in such instances and the method of subsequent handling of that participant's data was not disclosed.The morning dose was directly observed, and evening dose adherence was logged by a visiting field worker. Approximately twenty-eight per cent of participants in each group had a baseline Leptospira titer greater than 1:100.

Gastric irritation was the most common adverse effect reported. In Group I three participants were withdrawn for adverse events. One of these persons developed an erythematous rash after the first 
Sehgal 2000 (Continued)

dose, while the other two persons withdrawn experienced gastritis with persistent stomach pain and vomiting. Rates of less severe adverse events were not fully characterized.

\begin{tabular}{|c|c|c|}
\hline \multicolumn{3}{|l|}{ Risk of bias } \\
\hline Bias & Authors' judgement & Support for judgement \\
\hline $\begin{array}{l}\text { Adequate sequence gener- } \\
\text { ation? }\end{array}$ & Unclear risk & Unclear. \\
\hline Allocation concealment? & Unclear risk & Sealed envelopes, but no information if they were opaque. \\
\hline $\begin{array}{l}\text { Blinding? } \\
\text { All outcomes }\end{array}$ & Unclear risk & $\begin{array}{l}\text { Patient and laboratory were explicitly identified as blinded, but whether clin- } \\
\text { ical evaluators were blind to participants' assignment was not clear. Also, the } \\
\text { degree to which the vitamin B complex tablets used for placebo resembled the } \\
\text { intervention medication was not disclosed. }\end{array}$ \\
\hline $\begin{array}{l}\text { Incomplete outcome data } \\
\text { addressed? } \\
\text { All outcomes }\end{array}$ & High risk & $\begin{array}{l}243 \text { enrollees were not included in analyses nor were their data reported. } \\
\text { While laboratory findings were relayed in detail, clinical findings were not. }\end{array}$ \\
\hline $\begin{array}{l}\text { Free of selective report- } \\
\text { ing? }\end{array}$ & Low risk & Death and adverse events were included in their reporting of the data. \\
\hline $\begin{array}{l}\text { Free of baseline imbal- } \\
\text { ance? }\end{array}$ & Unclear risk & $\begin{array}{l}\text { Age was well disclosed, though gender distribution was less clear. Also, the na- } \\
\text { ture of potential exposures was not delineated by group - for instance, distrib- } \\
\text { ution of agricultural workers and students between the two groups. }\end{array}$ \\
\hline Free of early stopping? & Unclear risk & Unclear. \\
\hline Free of academic bias? & Low risk & Yes. \\
\hline $\begin{array}{l}\text { Free of source of funding } \\
\text { bias? }\end{array}$ & Unclear risk & Pfizer provided doxycycline. \\
\hline
\end{tabular}

Takafuji 1984

Methods Single site prospective, randomised trial executed in two phases with sequentially deployed troops to
the area of interest.
Participants Active duty army soldiers deployed to the Fort Sherman training area in Panama. During this period, likely all men predominantly less then 30 years of age. Exclusion criteria were narrow- allergy to tetra- cycline or receiving other antibiotic at time of enrolment.

Interventions

Pre-exposure prophylaxis with weekly administration of a single dose of two $100 \mathrm{mg}$ doxycyline hyclate capsules or identical placebo.

1079 participants were randomised into two groups, though 109 participants (distribution among groups unknown) were excluded during the study for concomitant antibiotic use. Following ranged from three to nine weeks.

Group I: 469 participants - doxycycline.

Group II: 471 participants - placebo.

Outcomes The primary outcome was laboratory identified infection. 
Takafuji 1984 (Continued)

Notes
Withdrawal occurred if participant was placed on any antibiotic over the course of the study. Manner of exclusion of leptospirosis in such instances and the method of subsequent handling of that participant's data was not disclosed. In three week period post-deployment, participants carried instructions on leave and clinical symptoms relied on self-report with uncertain validation. Thirteen per cent of participants had pre-existing Leptospira immunity though geographic exposures were not identified or specific serovar typing performed in order to assess potential impact. Also, distribution of these preimmune participants across intervention and control groups was not disclosed. Reports of clinical disease appear to have been mixed with other cases presenting outside of the study during the same period and so unable to evaluate intervention's effect on clinical outcomes.

Among those participants for who data was reported and analysed, thirteen in Group I and one in Group II experienced vomiting. All thirteen of these participants in Group I had ingested the doxycycline five to seven hours after their most recent meal whereas typically administration was within two hours of eating.

\begin{tabular}{|c|c|c|}
\hline \multicolumn{3}{|l|}{ Risk of bias } \\
\hline Bias & Authors' judgement & Support for judgement \\
\hline $\begin{array}{l}\text { Adequate sequence gener- } \\
\text { ation? }\end{array}$ & Low risk & Computer generated random assignments. Block randomisation employed. \\
\hline Allocation concealment? & Unclear risk & No information. \\
\hline $\begin{array}{l}\text { Blinding? } \\
\text { All outcomes }\end{array}$ & Low risk & Asserted double blinded trial design and reported use of identical placebo. \\
\hline $\begin{array}{l}\text { Incomplete outcome data } \\
\text { addressed? } \\
\text { All outcomes }\end{array}$ & High risk & Outcomes sought not explicitly stated. Also, analyses excluded 107 enrollees. \\
\hline $\begin{array}{l}\text { Free of selective report- } \\
\text { ing? }\end{array}$ & High risk & $\begin{array}{l}\text { In clinical outcomes in particular results confused with reporting of non-en- } \\
\text { rolled cases. Baseline serologic differences between the groups were not dis- } \\
\text { closed. }\end{array}$ \\
\hline $\begin{array}{l}\text { Free of baseline imbal- } \\
\text { ance? }\end{array}$ & Unclear risk & Distribution of pre-existing immunity not disclosed. \\
\hline Free of early stopping? & Unclear risk & $\begin{array}{l}\text { Sample size calculations not disclosed, though following time for serologies } \\
\text { appeared robust. }\end{array}$ \\
\hline Free of academic bias? & Low risk & Yes. \\
\hline $\begin{array}{l}\text { Free of source of funding } \\
\text { bias? }\end{array}$ & Unclear risk & Pfizer provided doxycycline and placebo. \\
\hline
\end{tabular}

\section{DATA AND ANALYSES}


Comparison 1. Pre-exposure prophylaxis with doxycycline

\begin{tabular}{|c|c|c|c|c|}
\hline Outcome or subgroup title & $\begin{array}{l}\text { No. of } \\
\text { studies }\end{array}$ & $\begin{array}{l}\text { No. of } \\
\text { partici- } \\
\text { pants }\end{array}$ & Statistical method & Effect size \\
\hline 1 Laboratory identified infection & 2 & 1722 & Odds Ratio (M-H, Random, 95\% Cl) & $0.28[0.01,7.48]$ \\
\hline 2 Adverse events, minor & 2 & 1722 & Odds Ratio (M-H, Fixed, 95\% Cl) & $11.33[2.12,60.46]$ \\
\hline $\begin{array}{l}3 \text { Clinical infection, laboratory con- } \\
\text { firmed }\end{array}$ & 1 & 782 & Odds Ratio (M-H, Fixed, 95\% Cl) & $0.44[0.22,0.88]$ \\
\hline 4 Death & 1 & 782 & Odds Ratio (M-H, Fixed, 95\% Cl) & $0.15[0.01,2.83]$ \\
\hline $\begin{array}{l}5 \text { Laboratory identified infection, base- } \\
\text { line IgM titer zero }\end{array}$ & 1 & 356 & Odds Ratio (M-H, Fixed, 95\% Cl) & $1.19[0.70,2.00]$ \\
\hline $\begin{array}{l}6 \text { Laboratory identified infection, base- } \\
\text { line IgM titer non-zero }\end{array}$ & 1 & 426 & Odds Ratio (M-H, Fixed, 95\% Cl) & $1.21[0.81,1.81]$ \\
\hline
\end{tabular}

Analysis 1.1. Comparison 1 Pre-exposure prophylaxis with doxycycline, Outcome 1 Laboratory identified infection.

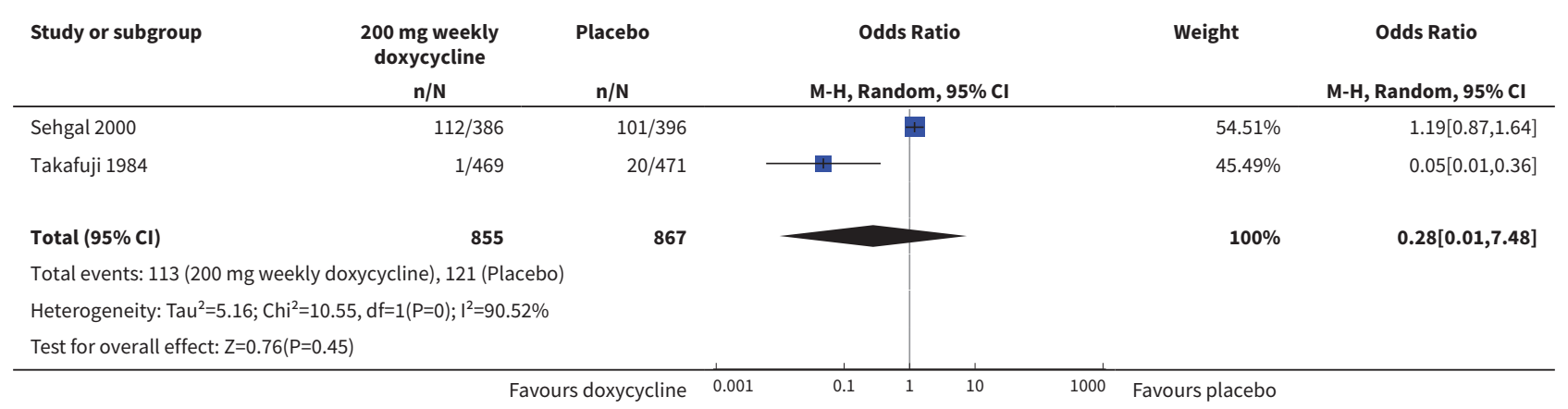

Analysis 1.2. Comparison 1 Pre-exposure prophylaxis with doxycycline, Outcome 2 Adverse events, minor.

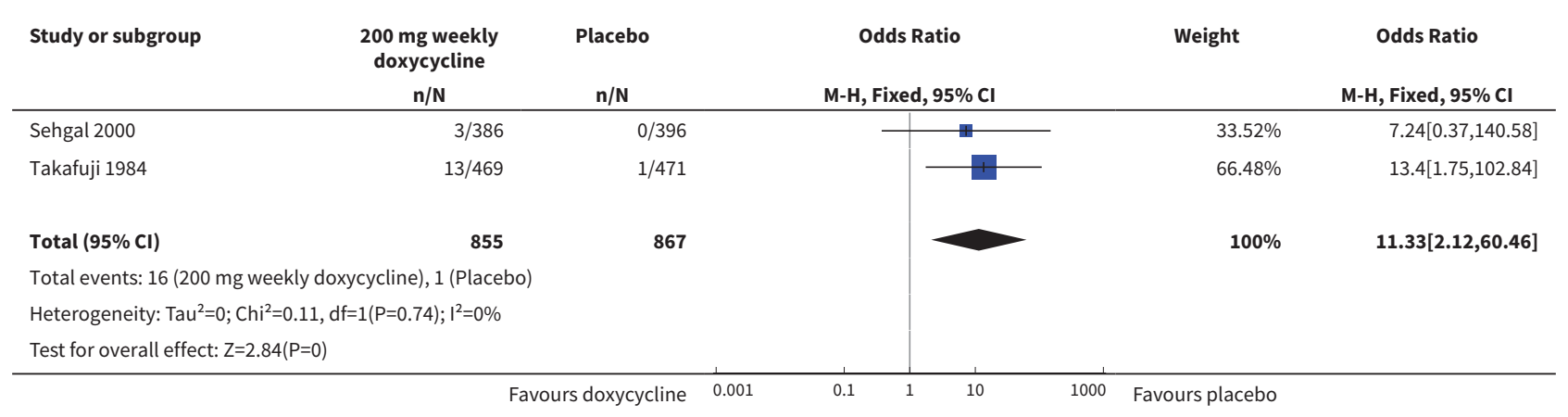


Analysis 1.3. Comparison 1 Pre-exposure prophylaxis with doxycycline, Outcome 3 Clinical infection, laboratory confirmed.

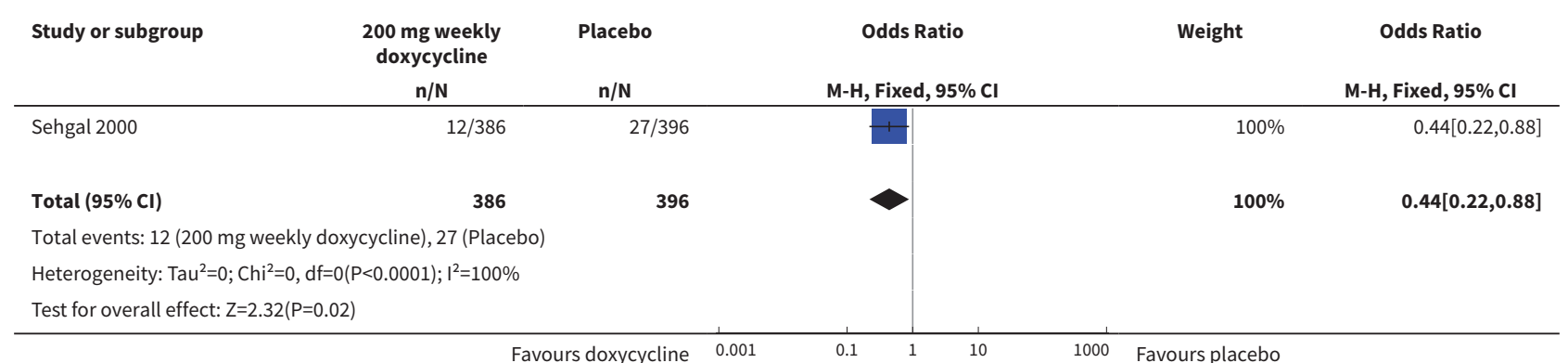

Analysis 1.4. Comparison 1 Pre-exposure prophylaxis with doxycycline, Outcome 4 Death.

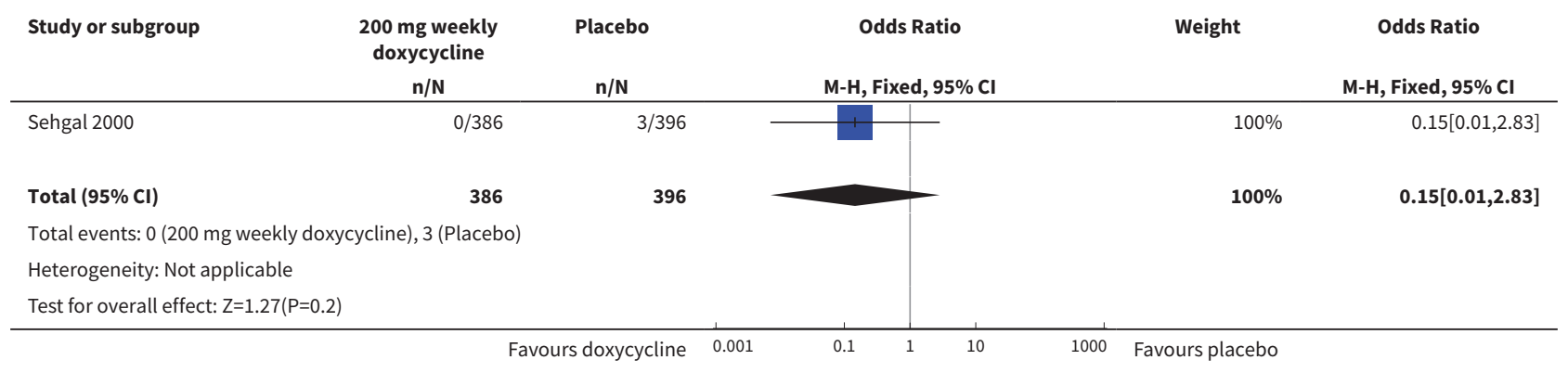

Analysis 1.5. Comparison 1 Pre-exposure prophylaxis with doxycycline, Outcome 5 Laboratory identified infection, baseline IgM titer zero.

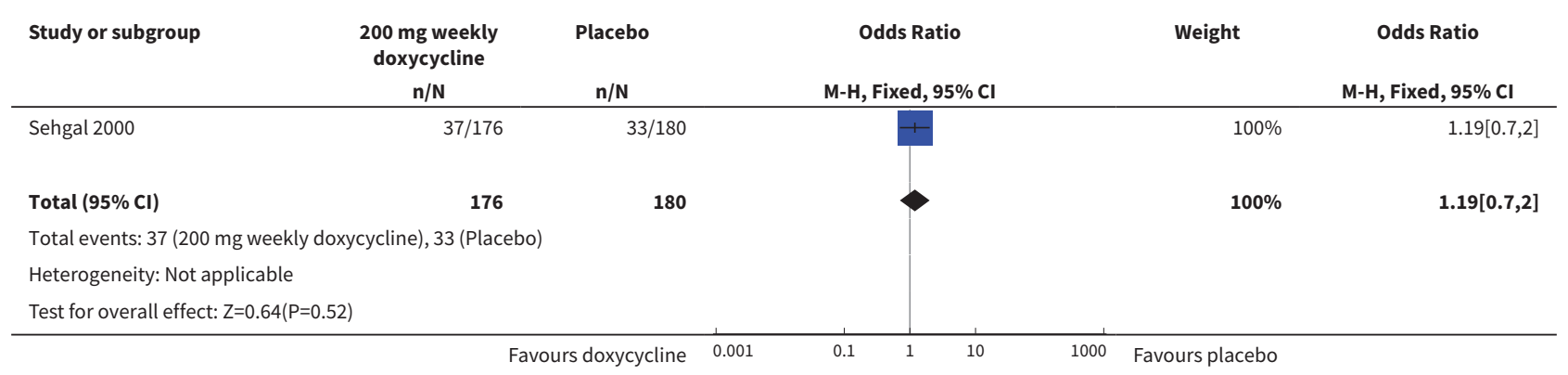

Analysis 1.6. Comparison 1 Pre-exposure prophylaxis with doxycycline, Outcome 6 Laboratory identified infection, baseline IgM titer non-zero.

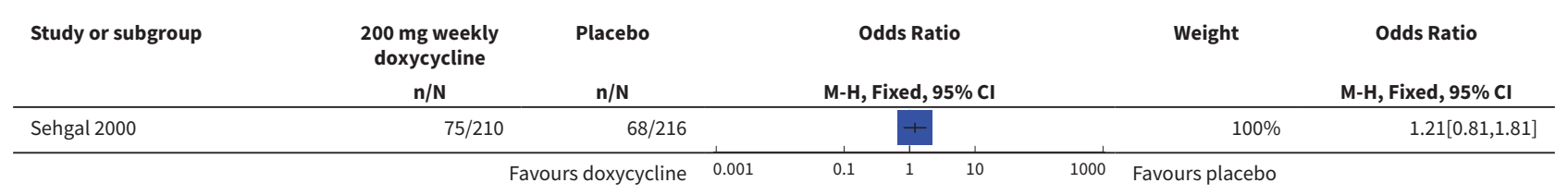




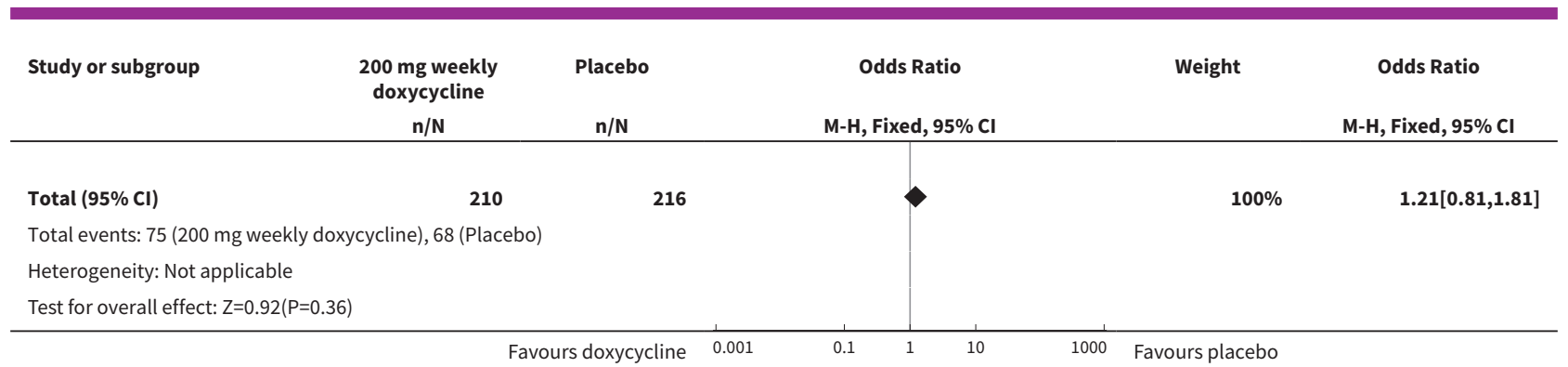

Comparison 2. Post-exposure prophylaxis with doxycycline

\begin{tabular}{llllll}
\hline Outcome or subgroup title & $\begin{array}{l}\text { No. of } \\
\text { studies }\end{array}$ & $\begin{array}{l}\text { No. of } \\
\text { partici- } \\
\text { pants }\end{array}$ & Statistical method & Effect size \\
\hline 1 Laboratory identified infection & 1 & 82 & Odds Ratio (M-H, Fixed, 95\% Cl) & $1.36[0.52,3.52]$ \\
\hline 2 Clinical infection, laboratory confirmed & 1 & 82 & Odds Ratio (M-H, Fixed, 95\% Cl) & $0.39[0.07,2.13]$ \\
\hline $\begin{array}{l}3 \text { Clinical infection, laboratory confirmed when } \\
\text { IgM+ at baseline removed }\end{array}$ & 1 & 71 & Odds Ratio (M-H, Fixed, 95\% Cl) & $0.52[0.09,3.01]$ \\
\hline
\end{tabular}

Analysis 2.1. Comparison 2 Post-exposure prophylaxis with doxycycline, Outcome 1 Laboratory identified infection.

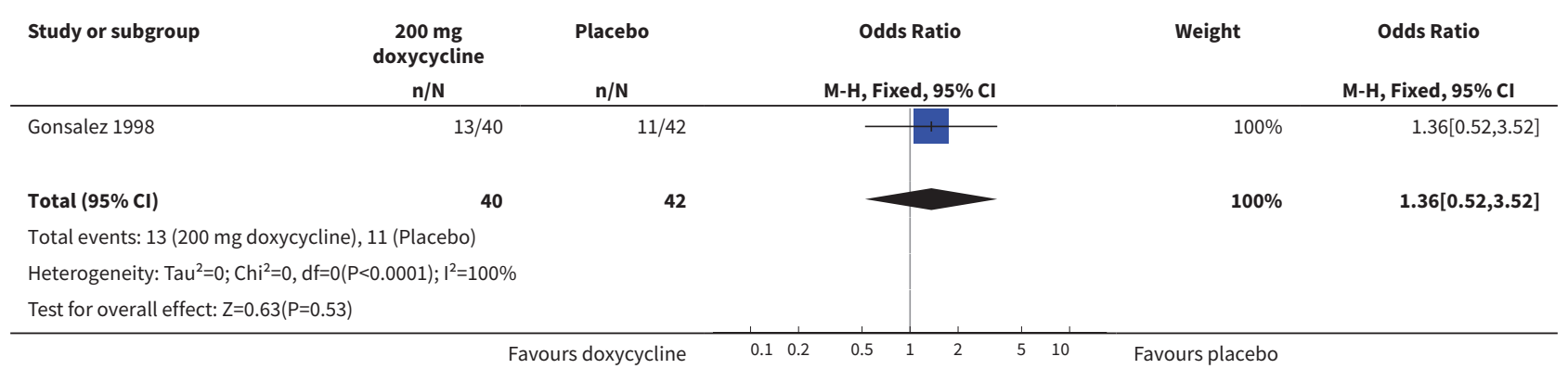

Analysis 2.2. Comparison 2 Post-exposure prophylaxis with doxycycline, Outcome 2 Clinical infection, laboratory confirmed.

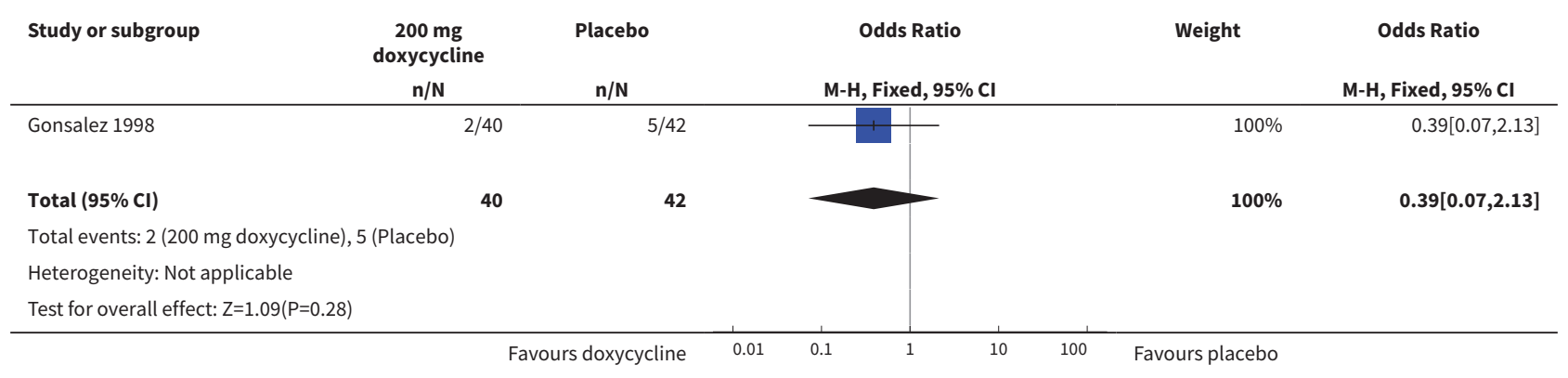


Analysis 2.3. Comparison 2 Post-exposure prophylaxis with doxycycline, Outcome 3 Clinical infection, laboratory confirmed when IgM+ at baseline removed.

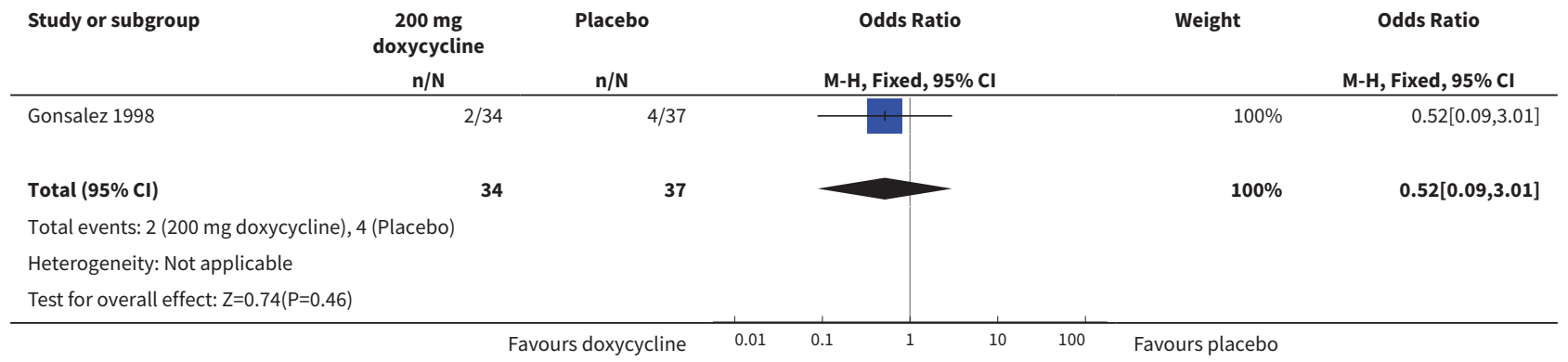

\section{APPENDICES}

\section{Appendix 1. Search Strategies}

\begin{tabular}{|c|c|c|}
\hline Database & Span of Search & Search strategy \\
\hline $\begin{array}{l}\text { Cochrane Hepa- } \\
\text { to-Biliary Group Con- } \\
\text { trolled Trials Register }\end{array}$ & January 2009. & leptospir* AND prophylax* \\
\hline $\begin{array}{l}\text { Cochrane Controlled } \\
\text { Trials Register (Cen- } \\
\text { tral) }\end{array}$ & Issue 4, 2008. & $\begin{array}{l}\text { 1. exp Antibiotic Prophylaxis/ } \\
\text { 2. prophylax*.mp. [mp=title, original title, abstract, name of substance word, sub- } \\
\text { ject heading word] } \\
\text { 3. } 1 \text { or } 2 \\
\text { 4. exp Leptospirosis/ } \\
\text { 5. leptospir*.mp. [mp=title, original title, abstract, name of substance word, subject } \\
\text { heading word] } \\
\text { 6. } 4 \text { or } 5 \\
\text { 7. } 6 \text { and } 3 \\
\text { 8. (random* or blind }{ }^{\star} \text { or placebo* or meta-analysis).mp. [mp=title, original title, ab- } \\
\text { stract, name of substance word, subject heading word] } \\
\text { 9. } 8 \text { and } 7\end{array}$ \\
\hline PubMed/MEDLINE & $\begin{array}{l}\text { From } 1950 \text { to Janu- } \\
\text { ary } 2009 .\end{array}$ & leptospirosis OR Leptospira AND prophylaxis AND human NOT vaccine \\
\hline MEDLINE (Ovid SP) & $\begin{array}{l}\text { From } 1966 \text { to Janu- } \\
\text { ary } 2009 .\end{array}$ & $\begin{array}{l}\text { 1. exp Antibiotic Prophylaxis/ } \\
\text { 2. prophylax*.mp. [mp=title, original title, abstract, name of substance word, sub- } \\
\text { ject heading word] } \\
\text { 3. } 1 \text { or } 2 \\
\text { 4. exp Leptospirosis/ } \\
\text { 5. leptospir*.mp. [mp=title, original title, abstract, name of substance word, subject } \\
\text { heading word] } \\
6.4 \text { or } 5 \\
7.6 \text { and } 3\end{array}$ \\
\hline EMBASE (Ovid SP) & $\begin{array}{l}\text { From } 1980 \text { to Janu- } \\
\text { ary } 2009 .\end{array}$ & 1. exp Antibiotic Prophylaxis/ \\
\hline
\end{tabular}


2. prophylax* ${ }^{*} \mathrm{mp} .[\mathrm{mp}=$ title, abstract, subject headings, heading word, drug trade name, original title, device manufacturer, drug manufacturer name]

3. 1 or 2

4. exp Leptospirosis/

5. leptospir*.mp. [mp=title, abstract, subject headings, heading word, drug trade name, original title, device manufacturer, drug manufacturer name]

6.4 or 5

7.6 and 3

\begin{tabular}{|c|c|c|}
\hline $\begin{array}{l}\text { Science Citation } \\
\text { Index Expanded } \\
\text { (http://portal.isi- } \\
\text { knowledge.com/por- } \\
\text { tal.cgi?DestAp- } \\
\text { p=WOS\&Func=Frame) }\end{array}$ & $\begin{array}{l}\text { From } 1900 \text { to Janu- } \\
\text { ary } 2009 .\end{array}$ & $\begin{array}{l}\text { leptospirosis OR Leptospira AND prophylaxis AND human NOT vaccine } \\
\text { Update Jan 2009: } \\
\text { \#3 20 \#2 AND \#1 } \\
\text { \#2 5.976 TS=leptospir* } \\
\text { \#1 } 49.842 \text { TS=prophylax* }\end{array}$ \\
\hline $\begin{array}{l}\text { Infectious Diseases } \\
\text { Society of America } \\
\text { (IDSA) }\end{array}$ & $\begin{array}{l}\text { Presented abstract } \\
\text { programs, national } \\
\text { meetings 2001, } 2003 \\
\text { to } 2006 \text {. }\end{array}$ & PDF search "leptospirosis" or "Leptospira" \\
\hline $\begin{array}{l}\text { American Society } \\
\text { of Tropical Medi- } \\
\text { cine and Hygiene } \\
\text { (ASTMH) }\end{array}$ & $\begin{array}{l}\text { Presented abstract } \\
\text { programs, nation- } \\
\text { al meetings } 2004 \text { to } \\
2007 \text {. }\end{array}$ & $\begin{array}{l}\text { Abstract search engine and PDF search, dependent upon year of meeting, with "lep- } \\
\text { tospirosis" or "Leptospira" }\end{array}$ \\
\hline $\begin{array}{l}\text { International Society } \\
\text { of Travel Medicine } \\
\text { (ISTM) }\end{array}$ & $\begin{array}{l}\text { Presented abstract } \\
\text { programs, interna- } \\
\text { tional meetings } 2003 \\
\text { to } 2007 \text {. }\end{array}$ & PDF search "leptospirosis" or "Leptospira" \\
\hline
\end{tabular}

\section{CONTRIBUTIONS OF AUTHORS}

Conceiving the review: [pre-existing]

Designing the review: DMB

Coordinating the review: DMB

Data collection for the review: DMB

Developing search strategy: DMB

Undertaking searches: DMB

Screening search results: DMB

Organising retrieval of papers: DMB

Screening retrieved papers against inclusion criteria: DMB

Appraising quality of papers: $\mathrm{DMB}, \mathrm{RL}$ Abstracting data from papers: DMB, RL

Writing to authors of papers for additional information: DMB

Providing additional data about papers: DMB by responding authors

Obtaining and screening data on unpublished studies: for abstracts, DMB

Data management for the review: DMB

Entering data into RevMan: DMB

Analysis of data: DMB

Interpretation of data: DMB, RL

Providing a methodological perspective: DMB, RL

Providing a clinical perspective: DMB

Providing a policy perspective: DMB, RL

Providing a consumer perspective: DMB, RL

Writing the review: DMB

Providing general advice on the review: RL, CHBG Staff

Securing funding for the review: NA 
Performing previous work that was the foundation of current study: NA

\section{DECLARATIONS OF INTEREST}

None known.

\section{DIFFERENCES BETWEEN PROTOCOLANDREVIEW}

Second author on the protocol was not available for execution of the review. As delineated, his duties were assumed by DMB and RL.

Intention-to-treat analyses were not possible as the selected trials lacked sufficient reported data, and though contacted authors did not provide supplemental information.

Similarly, only those sought outcomes for which data were available could be reported here.

\section{NOTES}

This review replaces the 'Antibiotics for preventing leptospirosis' review, last published by Guidugli et al (Guidugli 2000).

Additional affiliations.

DMB - Director, Military Tropical Medicine Course, Navy Medicine Manpower Personnel Training and Education (NAVMED MPT\&E), Bethesda MD; and, Assistant Professor, Division of Tropical Public Health, Departments of Preventive Medicine and Biometrics, and Medicine, Uniformed Services University, Bethesda MD.

RL - Chief, Communications, Standards, \& Training Division, Armed Forces Health Surveillance Center Silver Spring, MD; and, Professor, Division of Epidemiology and Biostatistics, Department of Preventive Medicine and Biometrics, Uniformed Services University, Bethesda MD.

These views are those of the authors and do not necessarily reflect those of NAVMED MPT\&E, AFHSC, Departments of the Army or Navy, Uniformed Services University, Department of Defense, or the U.S. Government.

\section{N DEX TERMS}

\section{Medical Subject Headings (MeSH)}

${ }^{*}$ Antibiotic Prophylaxis; Anti-Bacterial Agents [adverse effects] [ ${ }^{\star}$ therapeutic use]; Doxycycline [adverse effects] ["therapeutic use]; Leptospirosis [*prevention \& control]; Randomized Controlled Trials as Topic

\section{MeSH check words}

Humans 